\section{Justierung eines Messsystems}

C. Vidal ${ }^{1}$ und W.-R. Külpmann ${ }^{2}$

${ }^{1}$ Landeskriminalamt Niedersachsen, Dezernat 53 „Chemie“, Hannover, Deutschland

${ }^{2}$ Hannover, Deutschland

Synonym(e) Justierung

Englischer Begriff adjustment of a measuring system; adjustment
Definition Reihe von Tätigkeiten, die an einem Messsystem ausgeführt werden, sodass dieses festgelegte Anzeigen liefert, die Werten einer zu messenden Größe entsprechen (BIPM et al. 2012). Für Anmerkungen s. Literatur.

\section{Literatur}

BIPM, IEC, IFCC, ILAC, ISO, IUPAC, IUPAP, OIML (2012) Internationales Wörterbuch der Metrologie (VIM) Deutsch-englische Fassung. ISO/IEC-Leitfaden 99:2007, 4. Aufl. Beuth-Verlag, Berlin 